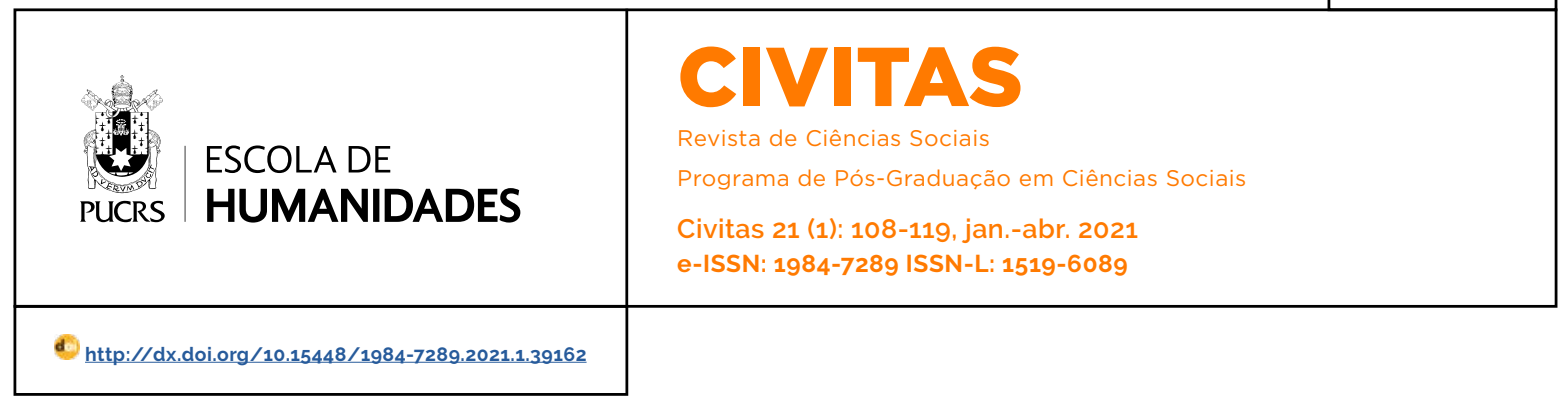

DOSSIÊ: TEORIA SOCIAL E SOCIOLOGIA EXISTENCIAL

\title{
Existências conjuntas e seus trajetos
}

Joint existences and their trajectories

\author{
Existencias conjuntas y sus trayectos
}

Miriam C. M. Rabelo ${ }^{1}$

orcid.org/0000-0002-5212-6129

mcmrabelo@uol.com.br

\section{lara Maria de Almeida \\ Souza ${ }^{1}$}

orcid.org/0000-0001-8430-7007

iara-maria@uol.com.br

Recebido em: 21 set. 2020.

Aprovado em: 5 nov. 2020.

Publicado em: 7 maio. 2021.
Resumo: Neste trabalho discutimos diferentes modos de existir-junto ou, mais especificamente, como certos seres se juntam em trajetórias de enredamento. A ideia, proposta por Souriau, de que as existências são não só plurais como também sempre capazes de tornar-se outras, de ganhar (ou perder) intensidade, constitui o ponto de partida de nossa reflexão. As formas de existir-junto de que falaremos aqui provêm de nossos diferentes campos de pesquisa (relações entre humanos e animais outros que humanos em um laboratório de pesquisa; relações entre seres mais que humanos e seus filhos humanos nas religiões afro-brasileiras). Interessa-nos refletir sobre os trajetos e técnicas através dos quais essas formas brotam e se fortalecem nesses campos.

Palavras-chave: Existências conjuntas. Formas de enredamento. Técnicas de existência.

Abstract: In this paper we discuss different modes of existing-together. More specifically, we deal with the question of how certain beings come together in trajectories of entanglement. Étienne Souriau's contention that existence is not only plural but always capable of becoming other and of gaining (or losing) intensity provides the starting point for our reflection. The modes of existing-together that we describe here come from our different fields of research (relations between humans and other-than-human animals in a research lab, and relations between human and more-than-human beings in Afro-Brazilian religions). We are interested in exploring the different trajectories and techniques that enable certain modes of entanglement to emerge and gain force in these fields.

Keywords: Joint existence. Modes of entanglement. Techniques of existence.

Resumen: En este trabajo discutimos diferentes maneras de se existir juntos o, más especificamente, cómo ciertos seres se juntan en trayectorias de enredamientos. La idea, propuesta por Souriau, de que las existencias no sólo son plurales sino que siempre son capaces de convertirse en otras, de ganar (o perder) intensidad, constituye el punto de partida de nuestra reflexión. Las formas de existencia de las que hablaremos aqui provienen de nuestros diferentes campos de investigación (relaciones entre humanos y animales distintos de los humanos en un laboratorio; relaciones entre seres más que humanos y sus hijos humanos en las religiones afro-brasileñas). Estamos interesadas en reflexionar sobre los caminos y técnicas a través de los cuales estas formas brotan y se fortalecen en estos campos.

Palabras clave: Existencias conjuntas. Formas de enredamiento. Técnicas de existência. 


\section{Introdução}

Neste texto tratamos de diferentes modos de existir-junto ou, mais precisamente, de algumas formas pelas quais seres diferentes se enredam e vêm a trilhar uma trajetória conjunta. Nossa questão traz ecos da discussão fenomenológica sobre intersubjetividade - seguindo a fenomenologia, tomamos esse "inter" como condição fundante tanto da subjetividade quanto da objetividade. Mas diferente da fenomenologia - ou ao menos de seus autores mais consagrados - nós partimos da ideia de que a existência se conjuga no plural, isto é, comporta mais de um modo de existir. Assim, na perspectiva que adotamos, se enredar e existir-junto não se restringem a relações entre humanos e abarca formas bastante heterogêneas. As formas de que falaremos aqui provêm de nossas distintas áreas de pesquisa (relações entre animais humanos e animais outros que humanos; relações entre seres mais que humanos e seus filhos humanos). Interessa-nos refletir sobre os trajetos e técnicas através dos quais certos enredamentos entre seres brotam e se fortalecem nesses campos. Ao fazê-lo queremos também experimentar com maneiras de descrever esses enredamentos em se fazendo, em processo de devir. Iniciamos o texto clarificando e desdobrando conceitualmente nossa questão chave.

O filósofo Étienne Souriau desenvolveu o conceito de modo de existência para avançar a ideia de que existir deve ser pensado no plural. Seu projeto consistia em modalizar a existência de forma que fosse possivel perguntar de quantos modos diferentes é possivel se existir. Para Souriau (2009) essa não é uma pergunta passivel de ser respondida por meio de um inventário exaustivo de modos, supostamente universais e atemporais. E não é uma pergunta endereçada exclusivamente aos filósofos, uma vez que envolve questões de interesse muito mais amplo. Tal como o autor os concebia, os modos de existência são históricos e não brotam nem realizam seu potencial se não contam com um investimento de seres concernidos com eles. Por isso o problema colocado por Souriau (2009) é especulativo e pragmático, conforme fica claro logo na introdução de Os diferentes modos de existência:
Uma questão prática também [...] saber se os seres que postulamos ou supomos, que sonhamos ou desejamos existem em uma existência de sonho ou de realidade [...] que tipo de existência está a ser preparada para recebê-los, está presente para os apoiar, ou ausente para aniquilá-los; ou se, equivocadamente, considerando apenas um tipo, vastas riquezas de possibilidades existenciais são deixadas sem cultivo pelo nosso pensamento e sem herdeiros pela nossa vida (Souriau 2009, 85).

As existências oscilam entre um mínimo e um máximo de realidade a depender do modo como são acolhidas e cultivadas. Duas ideias permitem qualificar melhor essa afirmativa: a existência de seres virtuais e a possibilidade aberta a todos seres de mudar seu plano de existência, de realizar-se de outra maneira, de percorrer uma trajetória diferente de realização. Seres virtuais são existências tênues, frágeis, potencialidades que cercam toda realidade como uma "aura de apelos" (Souriau 2009, 201). Podem nunca aceder à concretude (como testemunham os traços materiais de obras interrompidas ou os ecos de histórias abandonadas) e para fazê-lo precisam contar com outros sensiveis a seus apelos.

Os virtuais expõem o inacabamento existencial de todas as coisas. Envoltos por uma nuvem de virtualidades - de apelos para existir mais plenamente ou de outro modo - todos os seres são esboços de uma existência mais plena, mais forte, mais bem acabada. "Nada, nem mesmo nós, nos é dado senão em uma espécie de meia luz, em uma penumbra onde se esboça o inacabado, onde nada tem nem plenitude de presença, nem patuidade evidente, nem total realização, nem existência plena" (Souriau 2009, 15). Lapoujade (2017, 61) observa que uma das consequências chaves dessa ideia fundamental é deslocar a atenção das existências para os processos pelos quais elas se intensificam, se fortalecem, se transformam. Como tudo existe a meio caminho, em vias de tornar-se mais (ou menos) pleno, então o que existe não são propriamente seres, mas processos.

Nesse mundo de processos, os seres podem mudar de plano de existência: podem se descobrir enquanto possibilidade de ser de outro modo, de participar de uma trajetória diferente de realização. Trata-se de uma mudança de 
perspectiva, ou melhor, de abertura para outra perspectiva do mundo, uma guinada que faz com que o mundo se mostre diferentemente, a partir de novas qualidades e potencialidades. Como explica Lapoujade (2017, 63), essa guinada é justamente o que Souriau (2009) entende como acontecimento. A mudança súbita de perspectiva, entretanto, pode não ser levada adiante, o acontecimento pode não dar lugar a novas retomadas. Produzir a partir dele uma sequência, tornar estável uma existência que se anuncia, é matéria de instauração.

A instauração é o percurso pelo qual uma existência virtual, existência que é ainda lampejo fraco e um apelo para existir, vem a se realizar, a ganhar solidez e estabilidade como existência singular concreta. Uma existência nova precisa ser instaurada e para Souriau (2009) isso quer dizer que ela não se realiza sozinha e nem tem garantia de sucesso. Souriau (2009) escolhe o verbo fazer para falar de instauração justamente para ressaltar o esforço que é requerido nesse processo. Para vingar uma existência tem que ser feita - é resultado de um trajeto criativo. E esse trajeto é um drama de mais de um personagem: envolve sempre a participação de seres responsivos às incitações daqueles que existem ainda como puras virtualidades.

Em sua reflexão sobre a instauração, Souriau (2009) põe em evidência as relações que permitem uma existência se realizar - as formas de enredamento e participação de que se nutre uma existência em se fazendo, antes que possa emergir como existência autônoma e singular. Mas, conforme procuramos mostrar, formas de enredamento e participação podem ser elas mesmas modos de existência, emergindo e se desdobrando como diferentes apelos para existir-junto.

Para tratar do fazer instaurativo, Souriau (2009) usa o exemplo de um escultor moldando um bloco de massa com um cinzel, cada movimento, uma resposta ao ser virtual (a obra por fazer) que the atormenta e pede, insiste para ser instaurado, embora não the ofereça mais que uma situação questionante. O exemplo coloca em evidência a dimensão estética, dramática mesmo, da instauração como trajeto criativo: cada gesto do escultor é uma proposição à obra por fazer, na esperança de seu assentimento, mas também um risco, um gesto que pode pôr tudo a perder.²

O exemplo do escultor também permite entrever uma questão técnica, indissociável da estética do fazer instaurativo. Falar do trajeto pelo qual uma existência é adicionada ao mundo é também falar de técnicas que contribuem para a emergência do novo. Brian Massumi usa o termo "técnicas de existência" para se referir a técnicas desse tipo, que têm como alvo não objetos ou séries de objetos, mas potenciais de mudança. "Uma técnica de existência é uma técnica que toma como seu objeto o próprio processo, como a produção especulativa-pragmática de eventos orientados de mudança" (Massumi 2011, 14). Técnicas de existência operam através de abstração, mais especificamente através de um procedimento de abstração que Massumi (seguindo Peirce e Deleuze) chama de diagramar: extraem potenciais de mudança de uma experiência a fim de canalizá-los e torná-los disponiveis para as novas experiências que seguirão. Um diagrama é assim uma técnica construtivista para a emergência regulada de novas existências. Ou ainda: é uma técnica de devir.

Pragmaticamente falando, o diagrama (de uma nova existência) é a caixa de ferramentas das técnicas empregadas [...] para conduzir um conjunto selecionado de potenciais à concretude da nova existência (Massumi 2011, 100).

O corpo móvel e sensivel, observa Massumi, é também uma técnica de existência: canaliza a atividade ocorrendo em sua volta para sua própria atividade especial, operando, como qualquer outra técnica de existência, por abstração. É assim que precisamos entender a experiência sensivel: procedimento do corpo como técnica de existência, ela não é a operação de um sentido único e

2 É importante observar a esse respeito que a criação artística para Souriau (2009) está longe de corresponder à aplicação dos poderes de invenção do artista a uma massa inerte de material. É impossivel dizer na instauração quem, de fato, cria: se a obra depende do esforço do artista, ele não passa de meio para a realização da obra. 
nunca se descola do movimento: se abre para o mundo não para copiar a coisa percebida, mas para retomar e recriar em seus próprios termos, o potencial latente naquilo que percebe:

Nós nunca simplesmente registramos o que está à frente de nossos olhos. Com cada visada nós vemos qualidades imperceptiveis, nós vemos abstratamente potencial, nós implicitamente vemos uma dinâmica de vida, nós vivemos relação virtualmente (Massumi 2011, 43).

Merleau-Ponty (1994) chamou esse sentido latente na paisagem percebida de estilo: perceber para ele é retomar o estilo que as coisas nos propõem. Na sua formulação, corpo e coisa percebida relacionam-se como melodias em contraponto: a percepção não é a transposição pelos órgãos dos sentidos de um conjunto de traços objetivos da coisa, nem mesmo a imitação do estilo das coisas, é antes o acontecimento de melodias paralelas em contraponto ou um modo de sintonização.

Processos de sintonização podem ter um alcance mais amplo, para além da percepção, e desempenhar um papel importante na emergência de formas duradouras de enredamento entre seres. Mediante um procedimento de abstração um corpo pode se sintonizar com outros corpos vivos (humanos ou não) e mesmo com paisagens porque é capaz de perceber o potencial - de discernir e ser afetado pela dinâmica de vida que se enuncia por entre os traços sensiveis daquilo que percebe. Dois pontos importantes podem ser destacados a esse respeito. Primeiro: para haver sintonização não é necessário que haja uma semelhança "objetiva" entre aquilo ou aqueles que se sintonizam. Sintonizar-se é entrever uma dinâmica ou um estilo, através de um comportamento que já responde a ele que o acompanha e "canta em contraponto". Por isso - e esse é o segundo ponto - a sintonização é amodal: não se encerra em uma única modalidade sensorial, mas atravessa diferentes modalidades. Um corpo, ao se sintonizar com outro corpo, vibra com os movimentos do outro, o acompanha em contraponto. No entre-dois, delineia-se, junto com uma atmosfera ou tonalidade afetiva, o contorno abstrato do evento total.
Vejamos como esses processos se desenrolam nas relações entre pesquisadores e animais, pessoas e orixás

\section{História de Laura e dos animais}

Esta seção tratará da trajetória de Laura, pós- graduanda de uma instituição pública de pesquisa na área biomédica, e de animais de laboratório que produziram uma diferença em sua existência enquanto pesquisadora experimental. Ao considerarmos essa trajetória como um processo de instauração em que todas as partes são ativas (Souriau, 2009), damos a chance aos camundongos de laboratório com os quais Laura trabalha de mostrarem que as suas existências não se reduzem à pobre imagem usualmente associada a eles de seres que levam uma vida minúscula e sem glória, incrivelmente controlada e instrumentalizada. O modo como eles existem corporalmente, afetivamente e criativamente encontrou em Laura um outro ser disposto a acolher riquezas existenciais que no contexto do laboratório experimental apenas lampejam de modo tênue e pouco marcado. O cultivo da sensibilidade para com essas outras existências faz parte de sua própria instauração enquanto pesquisadora, também marcada por seu ser corporal e afetivo.

Laura pesquisa o modo como o sistema imunológico atua na resistência do organismo a infecções. As respostas a suas questões de investigação dependem da coleta de células de defesa produzidas por camundongos. Para sua obtenção, ela injeta uma gota de óleo no abdômen dele produzindo uma inflamação, atiçando assim os macrófagos a migrarem para o local. Enquanto me explicava o procedimento, Laura apontava para seu próprio abdômen recriando o ato de introduzir agulha no camundongo. Assim como ela, outros pesquisadores ao descreverem as manipulações feitas com animais frequentemente apontavam para si mesmos, mostrando em seu corpo aquela parte na qual faziam a manobra.

Além disso, há outro modo de Laura e seus colegas se alinharem aos bichos, eles refazem os movimentos e expressões do animal ao contar algo relativo a seu comportamento. Camun- 
dongos quando sacrificados na câmara de $\mathrm{CO}_{2}$ respiram profundamente buscando o ar que thes falta e Laura fazia uma longa respiração, como se lutasse para recuperar o fôlego ao falar sobre essas mortes. Hamsters, quando não querem ser tocados, abrem a boca e arreganham os dentes mostrando descontentamento. Dulce, uma mestranda, temia pegá-los porque, disse ela, eles faziam uma expressão malvada. Enquanto falava, a sua fisionomia tentava reproduzir a face feroz dos hamsters. Essas pequenas histórias mostram que gestos e expressões de camundongos ou hamsters, quando recriados pelos pesquisadores, carregam uma tonalidade afetiva - incômodo, medo - e esses não só recuperam a situação em que estavam em presença dos animais, como tentam estendê-la ao interlocutor.

Os exemplos nos falam também de formas de sintonização entre corpos e comportamentos que podem ser pensadas em termos de afinidades miméticas, que emergem na experiência de convivência entre humanos e animais que se assemelham e vivem em certa familiaridade (Galaty 2014). Acentuar a convivência entre esses diferentes seres como a fonte e a abertura de possibilidade para a sintonização, nos afasta de ideia de que tal fenômeno pode ser atribuído ao compartilhamento de características objetivas, genéricas e naturais - que the daria o fundamento - e nos aproxima da ideia de Souriau (2009) de que existências se fazem em relação umas com as outras. Isso significa que a ressonância de um corpo em outro não é nem reflexo de um dado objetivo, nem projeção subjetiva, é, antes, uma espécie de sintonização parcial criada na própria relação, no enredamento de vidas que se percebem e são capazes de responder umas às outras, como ponto e contraponto. Se Dulce pode expressar a face ameaçadora do hamster é porque ela captou seu estilo e a maneira como aquela criatura foi capaz de responder à presença, para ele atemorizante, da pesquisadora que tentava pegá-lo.

Animais são sensiveis e capazes de se sintonizar com aqueles com quem convivem, se alguém os aborda com medo, eles responderão com agitação, ao contrário, manter uma atitude serena os induz a agir de modo menos arisco. Pesquisadores são capazes de captar essas respostas. O ambiente também desempenha um papel importante na tonalização dos afetos, um lugar silencioso, onde as tarefas são feitas com cuidado e delicadeza produz efeitos em todos os participantes (Souza 2017). Os afetos podem ser transformados, por certo. O medo que dominava Dulce quando estava em presença dos hamsters fez com que ela hesitasse em seguir uma trajetória de pesquisadora, mas com a convivência, o temor acabou por se dissipar. Laura, diferente de Dulce, quando se iniciou na experimentação foi reconhecida como alguém que "tinha jeito" com os bichos, ela se sentia confiante para tocá-los e eles corresponderam a essa confiança. Não deixaram de tentar mordê-la ou fugir, mas ao longo do trabalho tendiam a se tornar mais abertos às manipulações, confirmando assim a sua habilidade. Essa confirmação não é o resultado previsivel de uma trajetória linear, Laura entrou no laboratório quase casualmente na Iniciação Científica, foi só então, no contato com bichos e outros entes, como células, proteínas, microscópios, que se descobriu pesquisadora experimental.

Camundongos estão há incontáveis gerações em laboratórios e para fazer-se pesquisadora experimental é preciso saber lidar com os animais e manipulá-los. Há um curso teórico para a iniciação nessa prática, mas Laura, assim como os demais, aprendeu efetivamente o oficio seguindo os passos de alguém mais experiente, observando os modos de tocar os bichos e sentindo os corpos e as suas reações. Conhecer os protocolos de manipulação é um requerimento imprescindivel para atuar nessa área, mas é insuficiente, cada um deve descobrir por si, com a ajuda de outros e dos próprios animais, a discernir as linhagens mais calmas ou ariscas, a não deixar os dedos disponiveis para mordida, saber quanto de pele segurar na pegada, como animais se movimentam, como preferem ser tocados, se estão estressados etc. Ninguém se torna um bom pesquisador experimental sem algum tipo de conexão com os animais, sem o reconhecimento nas variações das suas respostas e sem tentar corresponder a elas. Os camundongos ensinaram 
a Laura lições sobre os modos padronizados de agir, mas também, e de forma contundente, sobre o que escapa à rotina e à previsibilidade.

Por causa da resposta deles, um experimento em andamento foi suspenso. O acontecimento se deu quando Laura e uma colega estavam encarregadas da testagem de uma droga aplicada em camundongos em dias alternados. Antes do prazo estipulado para o final elas deram por encerrado o teste. Laura disse:

A gente parou (o teste). Eles ficavam agitados Parecia que ardia, sabe? No segundo dia eles já olhavam pra sua cara... (faz uma expressão assustada). Mesmo antes da gente pegar neles, eles ficavam muito agitados, fugiam na caixa pra não serem pegos. Quando a gente pegava, eles ficavam se debatendo tentando se soltar. Foi um estresse... Deve ter sido bem ruim pra eles. Provavelmente eles estavam sentindo dor. Era a impressão que a gente tinha, então dava uma pena saber que dia sim, dia não você vai causar dor e tal... Quando a gente tentava pegar eles, fechavam o olhinho assim (ela fecha os olhos), chegavam a fazer barulhinho, sabe? Como se estivessem gritando (Laura, com. pess., 12 de fevereiro de 2018).

Quando isso aconteceu, Laura já era relativamente experiente, sabia pegar camundongos, dar injeção, não se deixar morder e nem os deixar escapar. Isso compunha a sua rotina de trabalho. Ela esperava que com o decorrer do experimento tudo ocorresse como usual, depois de um tempo os bichos se acostumariam às manipulações e se tornariam menos relutantes. Mas os camundongos intensificaram a resistência, dramatizaram seu sofrimento, expresso na face assustada, nos olhos cerrados, na agitação do corpo se contorcendo ao ser pego, nas vocalizações. A dramatização deles afetou as pesquisadoras, conectou-as a sua dor - ao falar Laura recria a face e os olhinhos - e fez com que elas encerrassem o experimento. Esse acontecimento inesperado produziu uma transformação em Laura e passou a acompanhar como uma virtualidade todos os experimentos realizados daí em diante, agora ela sabe que protocolos de pesquisa podem ser cancelados pelos protestos dos animais.

Um camundongo, tempos depois, produziu outro efeito duradoura sobre Laura e fez com que ela colocasse em questão sua atitude frente ao trabalho experimental. Um dos aspectos trágicos da pesquisa experimental é que ao fim de cada teste todos os animais morrem, pois, órgãos e tecidos precisam ser extraídos para realização de análises. Laura costuma sacrificar camundongos com uma overdose de anestésicos. Eles inalam a droga, se entorpecem, desmaiam e, sem alarde, morrem. Enquanto isso Laura os observa, quando ela constata a cessação da respiração, mergulha o corpo do animal em álcool para a higienização e em seguida dá início à coleta do material biológico. Certo dia, tudo parecia correr como usual, até que um camundongo, estando já submerso em álcool, começou a soltar bolhas de ar, mostrando que estava vivo e tentava respirar. Assustada, ela retirou-o rapidamente do líquido, enxugou-o, esperou a respiração se regularizar, depois o recolocou no anestésico, esperou mais tempo, se certificou da morte e prosseguiu com o protocolo habitual.

Laura levou adiante o seu trabalho, esse pequeno acontecimento, entretanto, não findou aí, ele instituiu uma diferença na prática. O camundongo que surpreendentemente não morreu como esperado, fez com que ela colocasse questões sobre seu modo de atuar. Ela se viu cometendo um erro injustificável. Inclusive porque sabia, como os animais haviam ensinado, que há variações no tempo de morte e é preciso prestar atenção. Ela diz:

Depois de anos de experiência a gente se
assusta muito mais quando comete esse tipo
de erro, sabe, quando você tá no início o erro é
perdoável, mas depois de anos de experiência
dá uma sensação muito ruim de... você sabia
o que fazer e deu esse vacilo. [...]. Não tem um
tempo fixo, tipo dois minutos no anestésico,
você tem que ir observando ele parar de respi-
rar pra só depois tirar do anestésico e colocar
no álcool, nesse dia eu não tava com pressa,
não tinha acontecido nada e ele voltou a respi-
rar (Laura, com. pess., 12 de fevereiro de 2018).

Um camundongo quase morreu afogado em álcool, foi salvo para logo depois encontrar a morte por overdose de anestésico. Talvez outro pesquisador considerasse o episódio trivial. Mas o acontecimento, como disse antes, fez uma diferença em seu modo de praticar, sedimentou 
nela o senso de que seu trabalho não pode ser uma mera repetição desatenta de um protocolo porque os animais - mesmo com tantas semelhanças - são diversos, variam em suas respostas. Além disso, essa história reativou nela antigas inquietações sobre o ato de matar animais e sobre os riscos de tornar banais a morte e vida dessas criaturas. Porque ela convive com animais e é afetada por aquilo que eles fazem, matar não é trivial e o modo como isso é feito - mais ou menos cruel, mais ou menos cuidadoso - importa.

Um camundongo pode parecer estar morto, mas continuar vivo em mais de uma circunstância. Laura conta uma história, dessa vez em tom divertido, que aconteceu com uma colega: "Foi engraçado, parece que ele (camundongo) fingiu que tava morto, sabe?". A pesquisadora não se confundiu, ela foi enganada, "[...] ele tava inteiramente sem respirar e quando ela colocou ele na caminha, ele pulou e fugiu" (Laura, com. pess., 12 de fevereiro de 2018). O camundongo encontrou um lugar para se esconder e lá ficou, resistiu à tentação de sair quando lhe ofereceram ração. No dia seguinte, entretanto, impelido pela fome, foi pego na armadilha com comida. Como um animal de laboratório poderia aprender a fingir? Massumi (2017) pode nos ajudar a responder a essa pergunta ao conectá-la com a questão da dimensão estética da ação. Os animais brincam, observa Massumi. O gesto lúdico é uma força que induz uma mudança qualitativa na situação, brincar é uma abstração vivida, porque introduz uma diferença mínima entre a ação e a dramatização, entre o gesto lúdico e o gesto análogo que invoca. A brincadeira tem um rendimento estético, é um ato que é vivido por si. Mas, argumenta ele, e é isso que nos interessa aqui, todo ato, quer seja morder, fugir ou cortejar, sempre se faz acompanhar de um rendimento estético, porque sua execução envolve simultaneamente sua dramatização.

Acontece que os animais no biotério brincam. Normalmente eles fazem de conta que lutam (e as vezes brigam) e se exercitam no gesto lúdico com alguns objetos colocados em suas caixas.
Camundongos podem fingir porque reconhecem a distinção entre agir e dramatizar. É por conta dessa potência expressiva da ação e do corpo que os animais afetam os pesquisadores. As expressões e gestos que fazem ao narrar são também instâncias dessa potência vital.

Para Laura, existir como pesquisadora experimental é ter seu destino enredado ao das criaturas vivas que povoam a sua prática e compõem a sua trajetória, é estar aberta para outros corpos e sua potência. Por certo, esses seres suportam um ônus maior que ela na realização da pesquisa, mas as inúmeras gerações de camundongos ensinaram Laura a ser sensivel à colaboração deles e às suas formas de dramatizar sofrimento, também a tornaram capaz de acolher seus lampejos de criação e rir de sua capacidade de dissimular. Dos imprevistos, ela extraiu um potencial para a transformação da sua prática que se tornou mais aberta às virtualidades (Souriau 2009). Ela também se descobriu enquanto possibilidade de existir de outro modo, não mais como pesquisadora experimental, quando a consideração pela vida dos camundongos reacendeu nela hesitações relativas ao sofrimento e à morte dos animais.

\section{História de feituras (e quase feituras)}

Se na história de pesquisadores e animais em um laboratório temos o enredamento de dois corpos, nas histórias do candomblé a questão mostra-se um tanto diferente, embora, também aí movimento e ritmo sejam elementos chaves. Eles contribuem para fazer emergir uma das mais importantes formas de enredamento e existência conjunta de que se ocupam os terreiros: aquela que envolve uma pessoa e as entidades mais-que-humanas que a acompanham e se apossam de seu corpo. ${ }^{3}$ Ser-com nesse caso diz respeito ao enredamento de dois em um mesmo corpo. Na história que Maria José conta, os sinais desse enredamento se manifestaram muito cedo em sua vida:

\footnotetext{
3 No candomblé, entre as entidades que acompanham a pessoa, se destacam divindades africanas, conhecidas como orixás, inquices ou voduns. Aqui usarei apenas o termo orixá para falar destas divindades.
} 
Ah! Eu sou desse jeito, desde os sete anos que esse negócio me pega. Agora, se o meu pessoal cuidasse... Porque, se da parte de minha mãe tudo era envolvido com candomblé, você entendeu? [..] Quem me pegou, a primeira vez, foi Oxum. [...] Ai nesse dia a gente foi pra fonte. Ai minha tia estava lavando a roupa. [...] E tinha assim um rego e ficava aquela água limpa, e eu ficava cega, assim, olhando praquela água correndo, assim, aquela água bonita. [...] Ai eu comecei a cantar. [...] Cantei umas duas vezes, umas três vezes, aí eu caí de cabeça e dei a cabeça dentro daquele rego, dentro daquela água, entendeu? Aí, quer dizer, se o meu pessoal cuidasse, aí, eu já sabia, eu vinha com aquela fé, vinha cuidando até hoje, certo? Mas num cuidou nem nada (Maria José, com. pess., 15 de maio de 1994).

Ao descrever a chegada da sua Oxum, Maria José oferece pistas para entendermos como entidades das religiões de matriz africana se insinuam na vida das pessoas. Talvez, o primeiro ponto a notar é que aparentemente estamos longe de um modelo de sintonização gradual - Maria José foi tomada de surpresa, quando Oxum, divindade das águas doces, lançou-a no seu elemento: a menina ajudava a tia a lavar roupa quando foi subitamente jogada para dentro da água corrente.

Podemos dizer que o envolvimento de Maria José na paisagem de que Oxum é senhora, assim como a história de envolvimento de sua família com o candomblé criaram condições para o encontro. Apesar de repentino, esse encontro não deixou de envolver certa sintonização. Sintonizando-se com o ritmo das águas correntes - acompanhando esse ritmo com os olhos e com cantigas de orixá (literalmente cantando a paisagem), Maria José abriu-se para a possibilidade de experimentar Oxum. Subitamente foi tragada para dentro da cena que antes (apenas) admirava. O seu corpo caindo no córrego foi um modo de Oxum acontecer. Ou um modo de acontecerem juntas. Essa ambiguidade é reveladora. O evento ainda não é propriamente uma relação. É atravessado por uma tonalidade afetiva, mas parafraseando Massumi (2011, 113), está tudo ainda no entremeio ocorrente: na zona de indeterminação aberta entre o corpo e a paisagem, ou ainda, aberta no corpo, entre Maria José e Oxum.

Nem sempre a chegada das entidades no corpo de seus filhos se dá em meio a suas paisagens (naturais) de mato, água, ventos, terra. Muitas vezes acontece durante ritos que chamam e celebram as entidades. Os ritos, enquanto técnicas de existência, tornam paisagens virtualmente presentes, como tonalidades afetivas. Esboçando-se através de composições singulares de cantos, palmas, atabaques e movimentos ritmados, a presença virtual das paisagens dos orixás torna possivel a um corpo encontrar-se aberto à possibilidade de ser tomado por eles. Cria um campo propício para o evento: o orixá tomando o corpo como ritmo. Cabe notar, entretanto, que se a paisagem joga um papel importante na emergência das entidades, essa emergência não é nem uma interiorização do contorno da paisagem, nem uma exteriorização da entidade imaginada na paisagem. É o evento que irrompe em meio a ela.

O evento provoca uma guinada: abre seus participantes para um outro ponto de vista. Esse é sem dúvida o ponto de vista da entidade que assume controle, mas não só. A pessoa que pela primeira vez é pega por um orixá subitamente desconfia (ou descobre) que não é mais a mesma. Seguindo Souriau (2009), podemos dizer que seu plano de existência se transformou: se define agora pela sua condição de rodante ou de alguém que roda com santo. Muito mais que descrição de um atributo que a pessoa carrega, rodar com santo indica uma existência conjunta que tem sua própria trajetória. Pode crescer, tornar-se mais forte e intensa. Mas também pode perder força e ser relegada ao limbo. Foi o que aconteceu com dona Maria José: "ninguém cuidou" (Maria José, com. pess., 15 de maio de 1994).

No candomblé instaurar é encaminhar uma existência conjunta em uma trajetória de crescimento e maturação (Rabelo, 2014). Embora não comece e nem termine com a feitura (iniciação), essa trajetória tem na feitura um de seus momentos mais significativos. A feitura "faz" a pessoa e/com seu orixá individual. ${ }^{4}$ Se dona Maria José

4 Na feitura nascem, um para/com o outro, uma pessoa e o seu orixá individual (usualmente referido como santo/a). O santo é manifestação singular, única e insubstituivel de um orixá e está, portanto, vinculado à pessoa que é feita com ele. 
tivesse sido feita no candomblé, viria a cultivar o vínculo com a sua Oxum, a santa de quem é filha, ou que é dona da sua cabeça.

Virar no santo é expressão que fala dessa existência conjunta do ponto de vista do acontecimento - a chegada do santo (orixá) no corpo. Como rodar, virar ressalta o movimento, mas aqui a ênfase recai na mudança de orientação: virar é mover-se no (modo do) santo - movimento que, como vimos, já é o santo acontecendo na/com a pessoa. Embora seja uma possibilidade aberta a qualquer rodante, virar envolve uma sintonização fina com a paisagem em que se desenha o contorno do orixá e, geralmente, não acontece sem participação na vida do terreiro. Antes de virarem durante as festas, novatos veem-se na proximidade dos seus santos e assistem assustados os seus corpos moverem-se em um ritmo que não controlam. Virar é a experiência de serem completamente tomados pela entidade, de "adormecerem" quando o santo chega. Mas se quando vira, a pessoa "apaga", podemos ainda assim falar de um encontro ou mesmo de entrelaçamento entre dois seres?

Responder essa questão ajuda-nos a entender melhor o sentido de instauração no candomblé. Instaurar envolve de abrir lugar para outro ser onde antes parecia haver apenas um. Tem, assim, como efeito tornar possivel um caminho de individuação ao longo do qual a rodante e o santo podem emergir como participantes diferenciados da vida do terreiro. Mas o espaçamento criado não só depende da manutenção do vínculo pessoa-orixá através de sucessivas prestações e formas de cuidado, como se faz preservando uma zona de contato e indiferenciação - entre um santo e a sua filha humana há múltiplas ressonâncias e impregnações. Se por encontro entendemos o estar junto de seres com fronteiras nítidas e bem delimitadas, então o estar-junto da pessoa e do santo pode ser descrito como um quase-encontro ocorrendo na indeterminação de um entre-dois.

Para conduzir o processo instaurativo, o terreiro tem à sua disposição "uma caixa de ferramentas" - não só um modelo de instauração como também um conjunto de "instruções" ou procedimentos para lidar com cada etapa. Tanto o modelo que descreve a trajetória total, quando os procedimentos que descrevem as suas etapas são diagramas, no sentido atribuido por Massumi (2011). Para entendermos melhor como esses diagramas operam, vou descrever uma trajetória de instauração: a feitura de Beata, hoje mãe de santo, com terreiro aberto.

Segundo Mãe Beata conta, Ogum foi o primeiro santo que tomou seu corpo em uma festa no terreiro de Alaíde, mãe de santo em início de carreira que ainda não tinha filhos iniciados. 0 terreiro celebrou a chegada de Ogum, Alaide fez para ele uma oferenda, e o santo foi aos poucos tornando-se conhecido entre os frequentadores da casa. Mas não demorou muito e Beata se viu tomada por fortes dores de cabeça, tonturas e quedas. Alaide disse-lhe que ela precisava fazer o santo. Beata terminou concordando e foi logo formado um grupo de nove iaôs (noviças), todas mulheres. Deuandá, pai de santo de Alaíde, viria ajudá-la na feitura de seu primeiro barco (grupo de pessoas iniciadas juntas). Alice, filha de santo de outro terreiro, foi escolhida para ser mãe-pequena de Beata - aquela que, junto com a mãe de santo, cuidaria diretamente de Beata na sua feitura.

Beata seria feita para Ogum, o santo que rodava com ela. Mas nada aconteceu como previsto. Quando em um dos ritos iniciais da feitura, todas as suas irmãs de barco viraram no santo, Beata permaneceu acordada. Ogum não veio. Naquela noite o santo falou com Alaíde em um sonho: avisou que estava de partida e pediu-lhe um barco com as suas comidas favoritas. Na manhã seguinte Alaíde providenciou tudo: comprou um barco de brinquedo, colocou nele pequenas porções dos pratos apreciados por Ogum e arriou nas águas.

O problema é que Ogum partiu, mas nenhum outro orixá veio ocupar o seu lugar. Alaíde, Alice e Beata foram tomadas de preocupação: e se não viesse santo algum? Quando Deuandá chegou para ajudar Alaide, jogou os búzios e descobriu a causa do desacerto: o verdadeiro dono da cabeça de Beata era Logunedé, o jovem e belo filho de Oxossi e Oxum, orixá metá-metá que vive como mulher metade do ano e como homem na outra. 
Logun é santo raro e arredio, reluta muito até se mostrar. Embora Deuandá, Alaíde e Alice pedissem pela chegada de Logun no corpo de Beata, o santo se recusava a baixar. Deuandá separou Beata das outras iaôs do seu barco, para melhor cuidar dela e quem sabe criar condições mais favoráveis para a vinda de Logun. Durante sete dias, Alice fez um jejum de acaçá - comida votiva que concentra axé (energia vital) - pedindo a presença do santo. Ao fim do jejum, deu um banho de folhas em Beata, Logun despertou e a sua presença encheu o quarto da feitura. Deuandá imediatamente amarrou no tornozelo de Beata-virada-no-santo um pequeno guizo, o xaorô, segundo ele, para evitar que o santo partisse sem ser percebido. Ao final de uma série de preparativos, o kêle de Logun foi amarrado bem rente ao pescoço de Beata: feito com sete fios de contas, o kelê fala da sujeição da iaô a seu santo.

Beata juntou-se às irmãs no roncó. Ficaram recolhidas um mês, companheiras de feitura. Como parte dos ritos de feitura, o Logun de Beata (assim como os santos das outras iaôs) foi assentado em uma pedra (otá), colocado em uma sopeira de louça e alimentado com oferendas. Depois foi lavado e, oculto em seu recipiente, guardado junto com os outros santos da casa.

Quando o santo de Beata se apresentou paramentado na festa pública que encerra a feitura, o seu movimento já não era simples mudança de ritmo, mas a coreografia de Logun, respondendo aos atabaques e cantos que celebravam a sua chegada e desenhando no espaço a sua presença concreta e única.

A feitura de Beata envolveu uma série de procedimentos, cada um deles um diagrama de uma existência conjunta se fazendo: oferendas, jogo de búzios, assentamentos etc. Talvez a primeira coisa a dizer sobre eles é que a sua funcionalidade (ou a sua capacidade de fazer algo) é inseparável de seu apelo estético (a sua capacidade de expressar e dramatizar aquilo que fazem): é a sua força expressiva que thes permite tornar potenciais disponiveis para as experiências que se desenrolam.

Vimos que rodar-com-santo emerge inicialmente como uma experiência de movimento precedendo qualquer definição de sujeito móvel, de movimento como puro potencial de alteração. Podemos dizer que a feitura assegura que esse potencial de mudança seja conduzido de uma experiência à outra e circule entre elas: do santo rodando com a noviça ao seu assentamento em uma pedra; da configuração de búzios lançados no jogo ao santo que desperta no corpo; do corpo tombando/balançando/dançando (diagramas do santo como uma entidade viva que se move, tornando-se cada vez mais concreta) a oferendas contendo suas comidas prediletas (diagrama do santo como entidade viva que come).

A feitura como um todo é o diagrama dessa trajetória de enredamento. Mas em que sentido o diagrama opera? Uma resposta a essa questão é dizer que funciona como um modelo ideal que serve para ordenar e organizar o fluxo desordenado de experiências da iaô, impondo-lhe uma forma. Quando são empregados dessa maneira, diagramas exercem controles rígidos sobre os processos de construção e limitam ao máximo as possibilidades de inovação ou variação.

Souriau (2009) foi enfático ao afastar a instauração de processos de construção desse tipo. Conforme insistiu, a instauração deve ser entendida não como projeto a se realizar passo a passo pela transposição de traços imaginados a um material inerte, mas como um trajeto: um percurso que é feito também de encontros e surpresas, que põe compromissos à prova e incita a improvisação, que demanda atenção às particularidades de cada situação e frequentemente vê surgir atos absolutamente criativos. Pensando na feitura, talvez pudéssemos dizer: um percurso em que as indicações embutidas em um modelo não servem nem para sufocar a criatividade, nem para gerar insensibilidade à situação, senão para inspirar soluções a problemas que são sempre situados.

Essa para Massumi (2011) é uma (e certamente a mais interessante) forma de fazer e empregar diagramas: quando os padrões ideais e instruções gerais funcionam como restrições propiciadoras para seleções feitas em resposta ao desenrolar sempre único dos eventos. A feitura de Beata é 
um exemplo claro desse modo de construção: está orientada pelo diagrama de uma trajetória geral, mas ao longo de todo percurso, Alaíde e Deundá precisam se ajustar a acontecimentos que os pegam desprevenidos, que os fazem perscrutar a situação, começar de novo e experimentar.

\section{Considerações finais}

Procuramos explorar neste texto, a partir de dois contextos de pesquisa distintos, modos de existir junto e de construir trajetórias em enredamento com outros seres que não humanos. Um dos pontos de partida para essa exploração é a ideia, avançada por Souriau (2009), de que a existência precisa ser pensada no plural, não pode ser restrita a apenas duas modalidades de ser: sujeito e objeto. Para Souriau (2009), a existência não só se diferencia em modos como também segundo intensidades. Algumas existências são mais tênues e frágeis, enquanto outras são mais bem estabelecidas; de um modo ou do outro todas são inacabadas e sempre passiveis de metamorfoses, de ganhar ou perder força.

Para se realizar, uma existência precisa ser instaurada com a cooperação de outros. Esse é outro ponto importante da reflexão de Souriau (2009), que, para efeitos de nossa discussão, conectamos com uma questão relativa às técnicas que operam para assegurar que novas existências sejam adicionadas ao mundo. Massumi (2011) as chama de técnicas de existência.

No caso de Laura, a pesquisadora experimental, o seu trajeto depende de uma cooperação com animais que participam da ciência. A sua existência nesse plano se faz pela aquisição gradual de capacidades para lidar com camundongos, de sintonizar o seu corpo com o deles, de aprender a considerar as respostas dos animais. A prática científica nessa área - mas não só nela - é repleta de protocolos e exigência de padronização, mas a experiência com os animais, os seus corpos e os movimentos ensinam que eles sempre podem surpreender, mesmo a alguém experiente. O corpo móvel e sensivel de Laura, sintonizado e afetado pelo de outros seres, é ele mesmo uma técnica de existência que mantém
Laura aberta para novas experiências e surpresas, para perceber a potência de variação e invenção de animais que são feitos para a homogeneidade espelhadas em seus corpos virtualmente iguais e em suas vidas controladas e instrumentalizadas.

No caso do candomblé tratamos do enredamento de dois seres - pessoa e orixá - em um mesmo corpo. Esse modo de enredamento se insinua na vida das pessoas como movimento, entendido enquanto puro potencial de alteração. O movimento é o modo como, em geral, primeiro acontecem juntos um santo e sua filha rodante. A despeito do seu caráter inesperado, brota em um campo de envolvimentos, e não pode ser dissociado de formas sutis de sintonização com a paisagem. Entretanto, não é nem a interiorização da paisagem, nem a exteriorização na paisagem de uma figura imaginada. É o evento que irrompe em meio a ela e marca uma guinada: a descoberta de um novo plano de existência, de um apelo para existir de modo diferente. Na trajetória de Maria José esse apelo permanece como uma virtualidade não realizada, não deixa de existir, mas não é alvo de investimentos que lhe permitiriam crescer e ganhar força. Vimos na história de Beata como o terreiro de candomblé emprega um conjunto de técnicas para instaurar essas existências virtuais, dar-lhes força e estabilidade.

As técnicas de existência em cada caso, aquelas que permitiram acolher as surpresas e converter os acontecimentos em um potencial de abertura para outras experiências, envolveram o engajamento de corpos móveis e sensiveis - para animais e para divindades - capazes de sintonização e resposta, porque passiveis de serem afetados pela potência estética, dramática e expressiva de outros seres.

Por fim, é importante lembrar que quando Souriau (2009) pluraliza os modos de existência, ele o faz para salvar da destruição a variedade de formas de vida que povoam o mundo e não se localizam bem nas modalidades clássicas nas quais os existentes são divididos - sujeitos e objetos, eu e não eu, possivel e real - em especial aquelas existências que são mais frágeis e evanescentes, que existem em lampejos e esboços 
e contam com seu testemunho para intensificar sua realidade (Lapoujade 2017). Também é nosso esforço aqui, ao mostrar as trajetórias enredadas de pessoas, animais e orixás, dar testemunho da força afirmativa que é própria de suas existências, desdobrando potências que poderiam se ausentar ou ser esquecidas, que surgem de modo hesitante ou apenas esboçado, mas ganham outro plano e evocam, assim, tanto o inacabamento de todos os seres, quanto a abertura que há para todos de existir de outros modos.

\section{Referências}

Galaty, John G. 2014. Animal spirits and mimetic affinities: the semiotics of intimacy in African human/animal identities. Critique of Anthropology 34 (1): 30-47. https:// doi.org/10.1177/0308275X13510189.

Lapoujade, David. 2017. As existências mínimas. São Paulo: N-1 Edições.

Massumi, Brian. 2017. O que os animais nos ensinam sobre politica. São Paulo: N-1 Edições.

Massumi, Brian. 2011. Semblance and the event: activist philosophy and the occurrent arts. Cambridge: The MIT Press.

Merleau-Ponty, Maurice. 1994. Fenomenologia da percepção. São Paulo: Martins Fontes.

Rabelo, Miriam C. M. 2014. Enredos, feituras e modos de cuidado: dimensões da vida e da convivência no candomblé. Salvador: Edufba.

Souriau, Étienne. 2009. Les différents modes d'existence. Paris: Presses Universitaires de France.

Souza, lara Maria de Almeida. 2017. Afeto entre humanos e animais não humanos no biotério. RBCS 32 (94): 1-21. https://doi.org/10.17666/329407/2017.

\section{Míriam C. M. Rabelo}

Doutora em Ciências Sociais pela Universidade de Liverpool, Liverpool, Inglaterra; professora titular do Departamento de Sociologia e do Programa de Pós- Graduação em Ciências Sociais da Universidade Federal da Bahia (UFBA), Salvador, BA, Brasil.

\section{lara Maria de Almeida Souza}

Doutora em Ciências Sociais pela Universidade Federal da Bahia (UFBA), Salvador, BA, Brasil; professora adjunta do Departamento de Sociologia e do Programa de Pós-Graduação em Ciências Sociais da Universidade Federal da Bahia (UFBA), Salvador, BA, Brasil. 